Case Series

\title{
Arthroscopic remplissage: a valuable adjunct to arthroscopic Bankart's repair in shoulder instability
}

\author{
Gunjan Upadhyay*, Gaurav Gupta
}

\begin{abstract}
Department of Orthopedics, Consultant Orthopedic Surgeon, Calcutta Medical Research Institute, Kolkata, West Bengal, India
\end{abstract}

Received: 23 May 2020

Revised: 18 December 2020

Accepted: 19 December 2020

\author{
*Correspondence: \\ Dr. Gunjan Upadhyay, \\ E-mail: gunjan453@gmail.com
}

Copyright: () the author(s), publisher and licensee Medip Academy. This is an open-access article distributed under the terms of the Creative Commons Attribution Non-Commercial License, which permits unrestricted non-commercial use, distribution, and reproduction in any medium, provided the original work is properly cited.

\begin{abstract}
Current study present results of arthroscopic shoulder stabilisation surgery. 46 consecutive patients with recurrent anterior shoulder dislocations and less than $25 \%$ Glenoid bone loss were treated with arthroscopic surgery in 2017 2020. Arthroscopic repair of Bankart's lesion with capsular shift was performed in each. In 8 patients, where the Hill sach's lesion was "off track" or "engaging", arthroscopic remplissage was performed along with arthroscopic Bankart's repair. There was no recurrence of shoulder instability after a mean follow up of 1 year. This included the non-engaging Hill sach's group (treated with Bankart's repair) as well as the engaging or off track Hill sach's group (treated with Bankart's repair and remplissage). All patients went on to obtain full forward flexion, full abduction and internal rotation. The Bankart's and remplissage group had a mean of 8 degrees restriction of external rotation. SST scores and oxford scores had improved considerably on follow up in both groups Arthroscopic shoulder surgery provides a safe and reliable option in the management of recurrent shoulder dislocations. Arthroscopic remplissage is a useful adjunct to Bankart's repair when treating the difficult problem of a large engaging Hill Sachs lesion.
\end{abstract}

Keywords: Arthroscopic Remplissage, Bankart's lesion, Hill sach’s lesion

\section{INTRODUCTION}

Hill-Sachs lesion was described first by Broca \& Hartman in 1890. Hill-Sachs defect is a posterior-lateral compression fracture in the humeral head. In an anterior dislocation when the glenoid edge hits the humeral head this lesion appears. Hill and Sachs in 1940 classified the lesion into 3 types according to severity as, mildmoderate-severe, Hill-Sachs lesion were coined by Rowe et al. ${ }^{1,2}$ Significant bone loss concept coined by Burkhart $\&$ De Beer, which also pointed towards failure of arthroscopic Bankart repair surgery. ${ }^{3}$

Yamamoto et al gave concept of "Glenoid track". ${ }^{4}$ If Hill Sachs defect stays in glenoid track, no engagement in between Hill Sachs defect and glenoid occurs. However when extension of Hill Sachs defect is beyond the medial edge of glenoid track, engagement happens. Di Giacomo et al gave concept of on track \& off track Hill-Sachs lesion (Figure 6-7). For shoulder stability it's mandatory to convert an offtrack to an ontrack lesion. ${ }^{5}$ Purchase et al described "remplissage" in 2008 as an arthroscopic surgery with filling of Hill-Sachs defect with Infraspinatus tendon. ${ }^{6}$ Arthroscopic shoulder surgery provides a safe and reliable option in the management of recurrent shoulder dislocations. Arthroscopic Remplissage is a useful adjunct to Bankart's repair when treating the difficult problem of a large engaging HillSachs lesion. The Calcutta medical research institute, Kolkata was the site of study from 2017 to 2020. 


\section{CASE SERIES}

46 consecutive patients with recurrent anterior shoulder dislocations and less than $25 \%$ Glenoid bone loss were treated with arthroscopic surgery in 2017-2020. Arthroscopic repair of Bankart's lesion with capsular shift was performed in each. ${ }^{3}$ In 8 patients, where the Hill Sach's lesion was "off track" or "engaging", arthroscopic Remplissage was performed along with arthroscopic Bankart's repair. ${ }^{6}$

Patients were clinically examined (Figure 1), radiological evaluation done with X-ray \& MRI and PAC obtained. Apprehension sign positive. Anterior labral tear withless than $25 \%$ Glenoid bone loss detected radio logically.

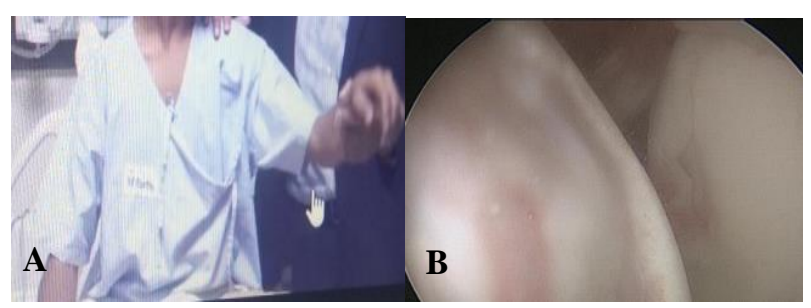

Figure 1: (A) Restricted range of motion, (B) HillSachs.

\section{Procedure}

Anterior labral tear and posterior Hill-Sachs defect were seen through arthroscopy. For posterior defect, spinal needle localization was done via poster lateral portals. Defect was prepared using motorized shaver and burr. Bone anchor was inserted into medial edge of defect. Retrieval of suture heads of anchor was done through infraspinatus and posterior capsule using grasper. Sutures were left as it is and arthroscopy was directed anteriorly. Post operative physiotherapy and X-ray (Figure 2) was done.

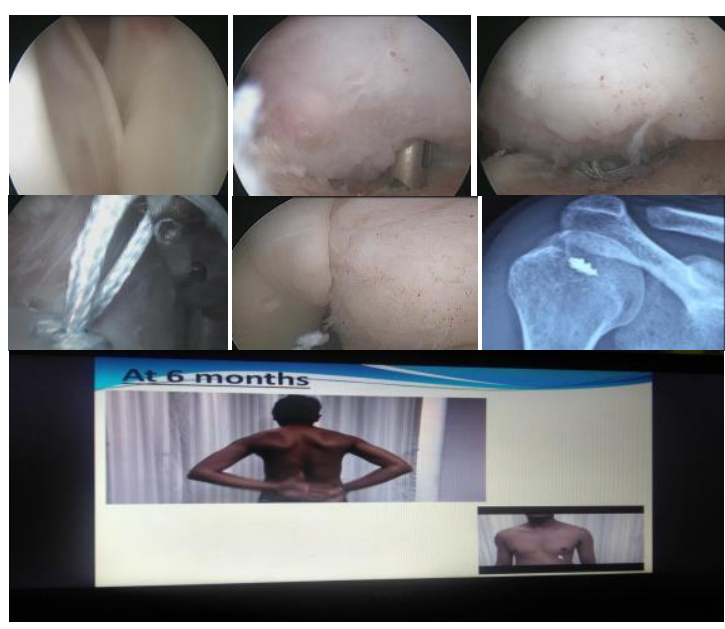

Figure 2: Operative and post operative $\mathrm{X}$-ray-Hill Sachs lesion and remplissage procedure done arthroscopically.
The follow-up period ranged for 1 year. The Rowe score improved significantly from a mean of 40.8 points preoperatively (ranging from 30 to 53 points) to a mean of 95.4 points postoperatively (ranging from 80 to 100 points) $(\mathrm{p}<0.001)$ (Figure 3). A total of $43(96 \%)$ of 46 shoulders were considered by the patients to be better as a result of the operation (Figure 4). The mean score of function improved from 18.3 points (range: $12-25$ points) preoperatively to 45.5 points (range: $41-50$ points) postoperatively. The stability component of the score improved significantly from a mean of 10.3 points (range: 6-13 points) preoperatively to 26.4 points (range: 24-30 points) postoperatively (Figure 6). The pain improved from a mean of 5 points (range: 3-6 points) preoperatively to 8 points (range: $7-10$ points) postoperatively. Similarly, the motion improved from a mean of 4 points (range: 2-6 points) preoperatively to 8 points (range: $7-10$ points) postoperatively.

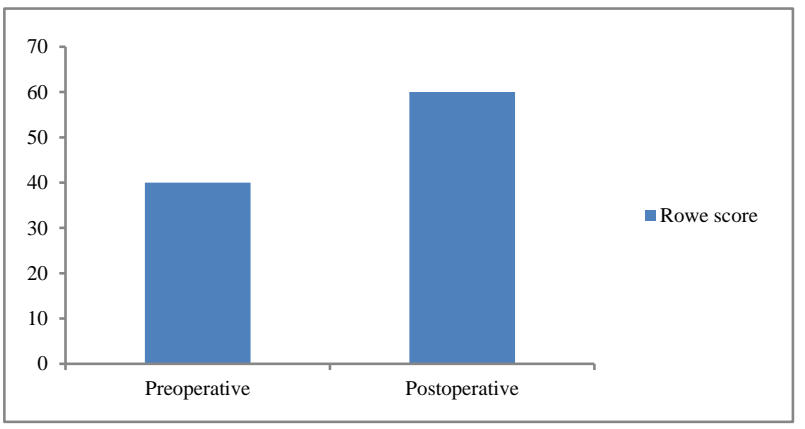

Figure 3: Rowe score at pre operative and postoperative status.

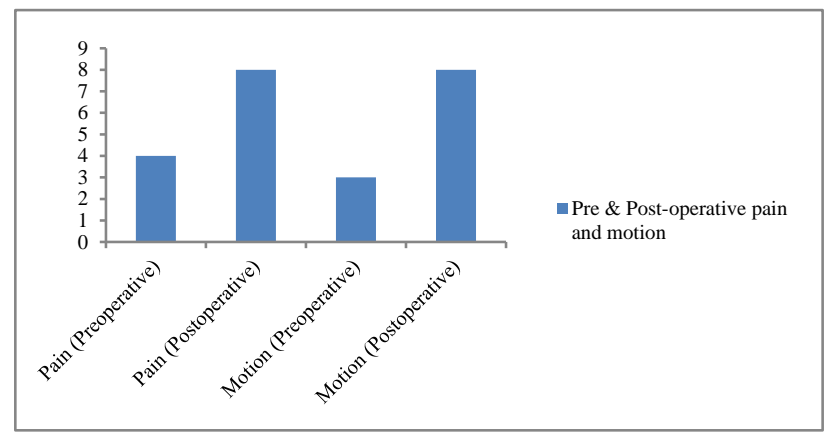

Figure 4: Pre and Post operative pain \& motion.

No surgical-site infection was encountered in the study, and there were no complications associated with suture anchors. None of the patients included in this study reported complaints of decreased shoulder range of motion, and all showed excellent degrees of shoulder external rotation.

\section{DISCUSSION}

The Remplissage is an arthroscopic technique used to treat anterior shoulder instability in patients with large Hills-Sachs lesions. ${ }^{1}$ 
Current indications for the procedure focus on patients with recurrent instability with an engaging Hill-Sachs lesion and minimal anterior glenoid deficiency, with intraoperative findings consistent with this diagnosis. ${ }^{3}$

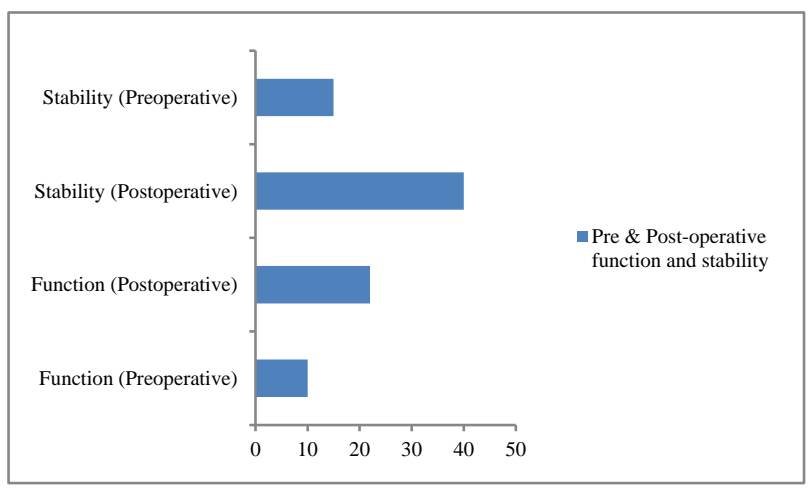

Figure 5: Pre and post operative function $\&$ stability.

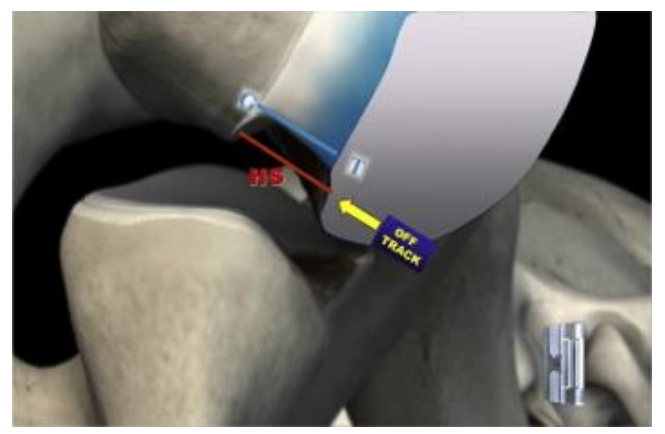

Figure 6: Off track lesion.

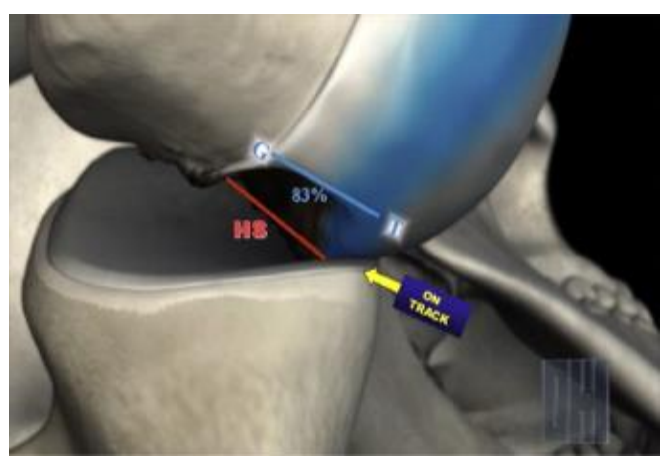

Figure 7: On track lesion.

The technique involves the use of arthroscopic tools to incorporate the tendon of infraspinatus and capsule within the humeral lesion to prevent continued engagement on the anterior glenoid and subsequent shoulder instability; in essence taking an intra-articular defect and turning it into an extra-articular defect. While the technical aspects of the technique can be modified, the procedure always involves the use of two anchors to fixate the tendon within defect. Different techniques can be utilized for efficiency or for patients with coexisting bony defects in addition to the humeral defect. Outcomes for this procedure have been favorable. For patients with large engaging Hill-Sachs lesions, remplissage has been proven to be superior to Bankart repair alone. ${ }^{5}$ Most patients have excellent outcome scores with minimal recurrent anterior shoulder instability reported. Furthermore, range of motion does not seem to be significantly decreased in most patients. The complications include minimal deficits in range of motion, namely a decrease in external rotation.

Gaps in knowledge concerning this technique remain, with some controversy regarding cut-off size of HillSachs lesion for which the remplissage technique is most effective. Furthermore, while there is concern for postoperative deficits in range of motion, this has not been shown to be statistically significant, and only clearly demonstrated in cadaveric studies. Prospective randomized cohort studies could further elucidate the impact on patient range of motion, pain, and shoulder outcome scores. Lastly, while this procedure seems to have gained widespread acceptance among the shoulder surgeon community, there have been no studies looking at the trends of the remplissage procedure within the United States in treating anterior shoulder instability. Nonetheless, remplissage is a successful arthroscopic procedure for anterior shoulder instability. Future research should be directed to better refine the indications, further describe potential complications, and supplement an understanding of its utilization in the population of patients with anterior shoulder instability.

\section{CONCLUSION}

Arthroscopic remplissage is a useful adjunct to Bankart's repair when treating the difficult problem of a large engaging Hill-Sachs lesion. Hence, through our study we want to bring the insight of post operative better results in terms of better motion, more stability and pain free movements of the shoulder after the successful operation.

Funding: No funding sources

Conflict of interest: None declared

Ethical approval: Not required

\section{REFERENCES}

1. Bankart AS. Recurrent or habitual dislocation of the shoulder-joint. Br Med J 1923;2:1132-3.

2. Lynch JR, Clinton JM, Dewing CB. Treatment of osseous defects associated with anterior shoulder instability. J Shoulder Elbow Surg. 2009;18:317-28.

3. Bushnell BD, Creighton RA, Herring MM. Bony instability of the shoulder. Arthroscopy. 2008;24: 1061-73.

4. Broca A, Hartmann H. Contribution a' l'e'tude des luxations de l'e'paule. Bull Soc Anat Paris. 1890;4: 416-23.

5. Flower WH. On the pathological changes produced in the shoulder-joint by traumatic dislocation: as derived from an examination of all the specimens illustrating this injury in the museums of London. 
Available at: https://wellcomecollection.org/works/ hahatzr4. Accessed on 20 February 2020.

6. Hill HA, Sachs MD. The grooved defect of the humeral head. Radiol. 1940;35:690-700.

7. Palmer I, Widen A. The bone block method for recurrent dislocation of the shoulder joint. J Bone Joint Surg Br. 1948;30B:53-8.

8. Burkhart SS, De Beer JF. Traumatic glenohumeral bone defects and their relationship to failure of arthroscopic Bankart repairs: significance of the inverted-pear glenoid and the humeral engaging HillSachs lesion. Arthroscopy. 2000;16:677-94.

9. Di Giacomo G, Itoi E, Burkhart SS. Evolving concept of bipolar bone loss and the Hill-Sachs lesion: from "engaging/non-engaging" lesion to "ontrack/off-track" lesion. Arthroscopy. 2014;30:90-8.

10. Antonio GE, Griffith JF, Yu AB. First-time shoulder dislocation: High prevalence of labral injury and agerelated differences revealed by MR arthrography. J Magn Reson Imaging. 2007;26:983-91.

11. Taylor DC, Arciero RA. Pathologic changes associated with shoulder dislocations. Arthroscopic and physical examination findings in first-time, traumatic anterior dislocations. Am J Sports Med. 1997;25:306-11.

12. Armitage MS, Faber KJ, Drosdowech DS. Humeral head bone defects: remplissage, allograft, and arthroplasty. Orthop Clin North Am. 2010;41:41725.

13. Weber BG, Simpson LA, Hardegger F. Rotational humeral osteotomy for recurrent anterior dislocation of the shoulder associated with a large Hill-Sachs lesion. J Bone Joint Surg Am. 1984;66:1443-50.
14. Hawkins RJ, Angelo RL. Glenohumeral osteoarthrosis. A late complication of the Putti-Platt repair. J Bone Joint Surg Am. 1990;72:1193-7.

15. Flatow EL, Miniaci A, Evans PJ. Instability of the shoulder: complex problems and failed repairs: Part II. Failed repairs. Instr Course Lect. 1998;47:113-25.

16. Purchase RJ, Wolf EM, Hobgood ER. Hill-sachs "remplissage": an arthroscopic solution for the engaging hill-sachs lesion. Arthroscopy. 2008;24: 723-6.

17. Connolly JF. Humeral head defects associated with shoulder dislocations: their diagnostic and surgical significance. Instr Course Lect. 1972;21:42-54.

18. Wolf EM, Arianjam A. Hill-Sachs remplissage, an arthroscopic solution for the engaging Hill-Sachs lesion: 2- to 10-year follow-up and incidence of recurrence. J Shoulder Elbow Surg. 2014;23:814-20.

19. Koo SS, Burkhart SS, Ochoa E. Arthroscopic double-pulley remplissage technique for engaging Hill-Sachs lesions in anterior shoulder instability repairs. Arthroscopy. 2009;25:1343-8.

20. Camp CL, Dahm DL, Krych AJ. Arthroscopic remplissage for engaging hill-sachs lesions in patients with anterior shoulder instability. Arthrosc Tech. 2015;4:e499-502.

Cite this article as: Upadhyay G, Gupta G.

Arthroscopic remplissage: a valuable adjunct to arthroscopic Bankart's repair in shoulder instability. Int J Res Orthop 2021;7:391-4. 